\title{
Nitrogen and phosphorus loading values in rainbow trout (Oncorhynchus mykiss) farming system in marine floating cage in the Southern Caspian Sea
}

\begin{abstract}
The aim of this study was to determine the loaded amounts of nitrogen $(\mathrm{N})$ and phosphorus (P) in the Rainbow trout farming system in the floating cage in the south of the Caspian Sea in 2018-2019. Two weight groups of fish (Group 1: $120 \mathrm{~g}$; Group 2: 300g) with 30,000 pieces were introduced to each floating cage. The offshore farm had three cages for group 1 (G1) and two cages for group 2 (G2). The fish culture period was 165 days and started in December and ended in May. At the end of the fish farming period, in groups 1 (G1) and 2 (G2), the weights were 780 grams and 1450 grams, respectively. The fish feed was semisubmerged extruded. The feed conversion ratio for G1 and G2 was determined 1.1 and 1, respectively. Fish survival rate was $95 \%$. The consumption of fish feed in G1 and G2 was 21 tons and 33 tons, respectively in each cage. The $\mathrm{N}$ content of the feed was $6.4 \%$ and the amount of feed $\mathrm{P}$ was $1.25 \%$. The amount of $\mathrm{N}$ and $\mathrm{P}$ in dry fish was $10 \%$ and $3.2 \%$, respectively. The amount of $\mathrm{N}$ and $\mathrm{P}$ loaded per 21 ton and 33 ton of fish feed in G1 and G2 was 873.75 and $1292.6 \mathrm{~kg} \mathrm{~N}$ and 112.02 and $150.3 \mathrm{~kg}$ P respectively. Also, the percentage of $\mathrm{N}$ and $\mathrm{P}$ in fish feed loaded in G1 and G2 was 65 and $61.2 \% \mathrm{~N}$ and 42.4 and $36.4 \% \mathrm{P}$, respectively. Therefore, in this marine farm, with the production of 149.34 tons of Rainbow trout, 5206.45kg N and 636.66kg P were loaded in the environment around the cage. These data are representing average conditions.
\end{abstract}

Keywords: marine cage culture, caspian sea, nutrient load, rainbow trout (Oncorhynchus mykiss) nitrogen and phosphorus loading
Volume 10 Issue 3 - 2021

\author{
SMVahid Farabi, M Golaghaei Darzi, M \\ Sharifian, H Nasrollahzadeh Saravi \\ Department of Aquaculture, Iranian Fisheries Science Research \\ Institute (IFSRI), Caspian Sea Ecology Research Center \\ (CSERC), Iran
}

Correspondence: Golaghaei Darzi, Department of Aquaculture, CSERC, IFSRI, Iran, Email smv_farabi@hotmail.com

Received: April 22, 202I | Published: June 29, 2021

\section{Introduction}

The ecosystem of the Caspian Sea is unstable against environmental and human changes. Enclosed coastal waters are subject to deterioration and eutrophication. Therefore, it is necessary to carry out any kind of human activity in the coastal area in the Caspian Sea region with environmental issues and political challenges. ${ }^{1}$ The marine cage culture began in the last decade (Since 2010) in the southern Caspian Sea region. ${ }^{2}$ Following this development, marine fish cage culture has been accused as a potential source of serious environmental impacts on its surrounding aquatic environment. ${ }^{3-5}$ In the other hand, The Caspian Sea region is the world's third largest reservoir of oil and natural gas after the Persian Gulf and Russia. Thus, management of its coastal waters requires efforts by all littoral countries $^{1}$. For this reason, the establishment of environmental quality objectives and standards should be an integral part of any framework plan for aquaculture development. ${ }^{6}$ The marine fish farming cages are having usually a high degree impacts interaction with environment. This system produces wastes that are released directly into the environment. Excess feed and fish waste are discharged from the farms and, if they accumulate, may alter the chemical processes of decomposition and nutrient assimilation. These wastes that are rich in organic matter and nutrients (nitrogen: $\mathrm{N}$ and phosphorus: $\mathrm{P}$ ) that released into coastal region. Additions of nitrogen and phosphorus to natural waters can cause eutrophication. ${ }^{7}$

Marine cage aquaculture operations are a recognized source of nitrogenous discharge released in the form of uneaten food, feces and metabolic wastes including ammonia and urea. ${ }^{8}$ The trend of increasing nitrogen levels in coastal waters due to anthropogenic sources is a concern worldwide, especially because it may contribute to algal blooms and eutrophication. ${ }^{9}$ Eutrophication effects of fish farming can be considered at several different scales, from local effects in the immediate surroundings of the fish farm to the contribution to large scale eutrophication ${ }^{10}$, e.g., in the entire south of the Caspian Sea.

Research has determined the amounts of nitrogen released from marine fish cages and the potential water quality and environmental effects of dissolved nitrogen. ${ }^{11}$ Recently, Norði et al. ${ }^{12}$ calculated that about $63 \%$ of nitrogen fed at a Rainbow trout Oncorhynchus mykiss farm in the Faroe Islands was lost as dissolved nitrogen. ${ }^{12}$ Olsen et al. ${ }^{13}$ constructed a mass balance estimate of nitrogen flow from a hypothetical Norwegian salmon farm producing 1000 metric tons (annual loading of $44 \mathrm{~kg}$ of nitrogen) of fish per year. ${ }^{13}$

The aim of this study was to determine the loaded amounts of nitrogen $(\mathrm{N})$ and phosphorus $(\mathrm{P})$ in the Rainbow trout farming system in the floating cage in the south of the Caspian Sea in 2018-2019.

\section{Materials and methods}

This study was carried out in an offshore fish farm in the southern region of the Caspian Sea $\left(36^{\circ}, 47^{\prime}, 12^{\prime \prime} \mathrm{N}\right.$ and $\left.51^{\circ}, 7^{\prime}, 50.2^{\prime \prime} \mathrm{E}\right)$ with a distance of $5.6 \mathrm{~km}$ from the coast. Water depth is $30 \mathrm{~m}$. (Figure 1).

The offshore farm had 5 circular polyethylene floating cages with a diameter of 20meters and a net height of 7 meters (volume is about $2200 \mathrm{~m}^{3}$ ) in 2018-2019. Two weight groups of fish (Group 1: 120g; Group 2: $300 \mathrm{~g}$ ) with 30,000 pieces were introduced to each floating cage. The marine farm had three cages for group 1 (G1) and two cages for group 2 (G2). The fish culture period was 165 days and started in December and ended in May. In this study used semi-submerged extruded fish commercial feed Faradaneh Company of Iran (Table 1). 


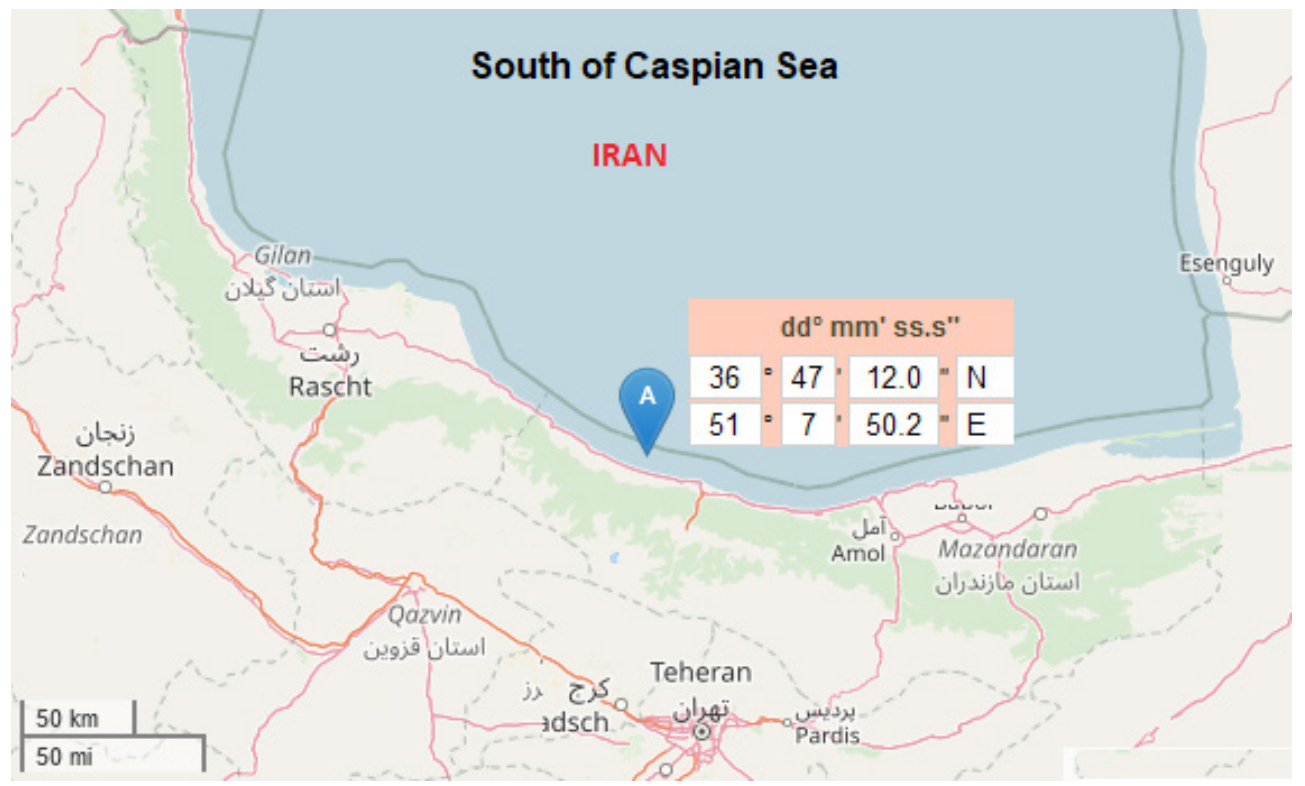

Figure I The South of Caspian Sea included in this study (A: fish farm).

Table I Chemical composition of fish commercial feed (Faradaneh Company, Iran)

\begin{tabular}{ll}
\hline Chemical composition & Ratio (\%) \\
\hline Crude protein & 40 \\
Crude lipid & 15 \\
Crude fibre & 3 \\
Ash & 9 \\
Moisture & 8 \\
Nitrogen & 6.4 \\
Phosphorus & 1.25 \\
\hline
\end{tabular}

The analysis of nitrogen and phosphorus for feed and fish were carried out kjeldahl and vanadomolybdophosphoric acid methods, respectively. ${ }^{14}$ The Rainbow trout are $25 \%$ dry matter that contains $10 \%$ nitrogen $(\mathrm{N})$ and $2.7 \%$ phosphorus $(\mathrm{P})$. Nutrient loads to a production system can be estimated as the amounts of nitrogen and phosphorus in feed, minus quantities of these two nutrients in fish at harvest. $^{?}$

After 165 days of feeding experiment the fish were counted to determine the survival rate (SR) according to the following equation in each cage (Eq. 1):

$$
S R(\%)=\frac{\text { Number of Fish at the End of rearing }}{\text { Number of Fish introduced to the cage }} \times 100
$$

The weight of the fish was measured with a scale of 1 gram at the beginning and end of the rearing period in each cage.

The average weight gain (AWG) were determined with the difference between the mean of initial and mean of final weights of fish at 165 days of rearing period in each cage, according to the following equation 15 . (Eq. 2):

$$
A W G(g)=\text { intial Mean weight }(g) \text { - final Meanweight }(g) \text { (Eq. 2) }
$$

The feed conversion ratio (FCR) was calculated according to the following equation in each cage. ${ }^{16}$ (Eq. 3):

$$
\mathrm{FCR}=\text { Feed given } / \text { AverageWeight Gain }(A W G)
$$

The feed conversion ratio (FCR) was calculated according to the following equation in each cage. ${ }^{16}$ (Eq. 3 ):

$$
\begin{aligned}
& \mathrm{FCR}=\text { Feed given } / \text { AverageWeight Gain }(A W G) \\
& \text { Phosphorus Inputsin Feed }(P I F)=\text { Feed } \times \text { FeedP }
\end{aligned}
$$

Nutrient removal in fish:

$$
\text { Nitrogen Removal in Fish }(N R F)=(\text { Fish } \times 0.25) \times \text { FishN }
$$

$$
\text { Phosphorus Removal in Fish }(P R F)=(\text { Fish } \times 0.25) \times \text { FishP }
$$

The equations for nitrogen and phosphorus loads are given in (1) and (2).

$$
\begin{gathered}
\text { Nitrogen load }(\operatorname{kg} \text { of } N)=(N I F-N R F) \\
\text { Phosphorusload }(\operatorname{kg} \text { of } N)=(P I F-P R F)
\end{gathered}
$$

Feed: feed given; Feed N: percentage nitrogen content of feed; Feed P: percentage phosphorus content of feed.

Fish: Average Weight Gain; Fish N: percentage nitrogen content of fish; Fish P: percentage phosphorus content of fish.

\section{Results}

The Performance and feed utilization for G1 and G2 was determined (Table 2). A total of 149.34 tons (G1: 66.690 tons and G2: 82650 tons) of fish were caught from this site after 165 days.

The amount of $\mathrm{N}$ and $\mathrm{P}$ loaded per 21 ton and 33ton of fish feed in each cage in G1 and G2 was $873.75 \mathrm{~kg}$ and $1292.6 \mathrm{~kg} \mathrm{~N}$ and $112.02 \mathrm{~kg}$ and $150.3 \mathrm{~kg}$ P respectively. The Table 3 has been showed estimates of nitrogen and phosphorus released per $1000 \mathrm{~kg}$ feed in Rainbow trout marine cage culture systems in the south of the Caspian Sea. 
Therefore, in this marine farm, with the production of 149.34 tons of Rainbow trout, $5206.45 \mathrm{~kg} \mathrm{~N}$ and $636.66 \mathrm{~kg}$ P were loaded in the environment around the cage. These data are representing average conditions.

Table 2 Performance and feed utilization of Rainbow trout in marine cage culture systems in south of Caspian Sea

\begin{tabular}{llll}
\hline & Group I & Group 2 & Total \\
\hline Initial mean weight $(\mathrm{g})$ & $120 \pm 12$ & $300 \pm 18$ & - \\
Final mean weight $(\mathrm{g})$ & $780 \pm 23$ & $1450 \pm 65$ & - \\
Average Weight Gain of fish:AWG (g) & 660 & 1150 & - \\
fish introduced to the cages (number) & 90000 & 60000 & - \\
Number of cage & 3 & 2 & 5 \\
Harvested in fish (number) & 85500 & 57000 & 142500 \\
Survival Rate: SR (\%) & 95 & 95 & - \\
Harvested in fish (ton) & $66.69 \pm 0.3$ & $82.65 \pm 0.5$ & 149.34 \\
Total AWG (ton) & 56.43 & 65.55 & 121.98 \\
Total feed given (ton) & 63 & 66 & 115.42 \\
FCR & 1.1 & 1 & - \\
\hline
\end{tabular}

*These data are representing average conditions

Table 3 Estimates of nitrogen and phosphorus released per $1000 \mathrm{~kg}$ feed in Rainbow trout marine cage culture systems

\begin{tabular}{|c|c|c|c|c|c|c|c|c|c|}
\hline \multirow{3}{*}{ Type of fish culture } & \multirow{2}{*}{\multicolumn{2}{|c|}{ Feed }} & \multirow[t]{3}{*}{ FCR } & \multirow{2}{*}{\multicolumn{2}{|c|}{$\begin{array}{l}\text { Whole Body } \\
\text { composition } \\
\text { (Dry Matter Basis) }\end{array}$}} & \multicolumn{4}{|c|}{ System nutrient loads } \\
\hline & & & & & & \multicolumn{2}{|c|}{ (kg// 000 kg Feed) } & \multicolumn{2}{|c|}{ (\% Feed Input) } \\
\hline & $\mathrm{N} \%$ & $\mathrm{P} \%$ & & $\mathrm{~N} \%$ & $\mathrm{P} \%$ & $\mathrm{~N}$ & $P$ & $\mathrm{~N}$ & $P$ \\
\hline G I & 6.4 & 1.25 & I.I & 10 & 3.2 & 41.6 & 5.3 & 65 & 42.4 \\
\hline G 2 & 6.4 & 1.25 & I & 10 & 3.2 & 39.17 & 4.55 & 61.20 & 36.4 \\
\hline
\end{tabular}

\section{Discussion}

The feeds applied in commercial aquaculture increase nutrients value in the environment. Actually, the resolving discharge of nutrients from aquaculture operations is an issue for conservation of environment. In the last decade, due to the increase in nutrients, unusual phenomena have occurred in the southern region of the Caspian Sea. Harmful algae blooms, mullet disease, Gobiidae death are some of the important cases of these emerging phenomena. On the larger scale, the anthropogenic nutrient load in south of the Caspian Sea is in most cases dominated by agricultural runoff and municipal sewage. ${ }^{2}$

Although this should not be used as a reason to allow unusual emissions from fish farms sea cage, it makes it is difficult to distinguish the large-scale eutrophication effects of fish farms Sea cage from that of other nutrient sources in the south of the Caspian Sea. ${ }^{3}$ The more important effects are found on the local and region scales, where fish farms in many cases are the dominating nutrient sources effective. ${ }^{19}$

In Europe, considerable attention has been given to limiting inputs of nitrogen and phosphorus in feed to fish cages as a means of reducing environmental loads. Little can be done to lessen loads nutrients other than improve feed conversion efficiency or reduce nitrogen and phosphorus concentrations in fish feeds. ${ }^{7}$

There are cases that, salmon fed diets with partial fish meal replacement by plant proteins reduced loads nutrients, but, decreased growth rates and reduced nutrient digestibility and gut health compared to standard fish meal-based diets. ${ }^{19,20,21}$ Thus, there is a limit to how much nitrogen and phosphorus concentrations can be reduced without sacrificing feed quality. ${ }^{7}$

In addition to the above, the results of this study showed that another strategy can be used to reduce nitrogen and phosphorus loading into the environment. Because, in cage culture or any other fish culture, all nutrients not retained in fish enter the surrounding water and some nutrients are used to grow and increase the weight of fish.

Recently, Norði et al. like this research (G1: 65\%; G2: 61.2\%) calculated that about $63 \%$ of nitrogen fed at Oncorhynchus mykiss farm was lost as dissolved nitrogen. ${ }^{12}$ This study has shown that by selecting fish with higher weights at the period of cage rearing, it is possible to reduce the nutrients to the environment during rearing (Table 3).

Pulatso $^{22}$ has been showed that in Oncorhynchus mykiss cages in which extruded feed was used, the nitrogen load was estimated to be between 33.47 and $25.97 \mathrm{~kg} \mathrm{t}-1$ of fish produced, and the phosphorus load was estimated to be between 7.32 and $7.96 \mathrm{~kg}$ t-1offish produced ${ }^{22}$ But, in this study was estimated nutrient loading less than Pulatso (2008) study (Table 3) 22 , Because the FCR was determined in this study (1 and 1.1) less than the Pulatso study (1.25-1.38). ${ }^{22}$ Therefore, feed conversion ratio is the most important factor in the rate of nutrient loading in fish farming. 
However, the weight of each of the fish in G1 and G2 increased 6.5 times and 4.8 times the weight of the fish, respectively. But the final biomass production in $\mathrm{G} 2$ was higher than $\mathrm{G} 1$ and the amount of food consumed G2 was less than G1.

On the other hand, in fish weighing more than one kilogram (1450grams to 780grams) the price of fish meat is higher in the market. It seems that introducing higher weight fish to the marine cage culture system is also more economically appropriate.

\section{Conclusion}

The Caspian Sea is a closed sea and is very fragile. In recent years, unusual phenomena such as algal blooms and the groups' death of some wild fish have occurred in the sea. Therefore, in this sea, it is necessary that any human activity, especially fish farming in cages, which affects the ecosystem of the environment, be done with caution and environmental considerations. As a result, the data of this research can be used to management of fish production plan in the southern region of the Caspian Sea.

\section{Conflicts of interest}

The authors declare no conflict of interest.

\section{Acknowledgments}

None.

\section{Funding}

None.

\section{References}

1. Nadim F, Bagtzoglou A.C, Iranmahboob J. Management of Coastal Areas in the Caspian Sea Region. Environmental Issues and Political Challenges, Coastal Management. 2006;34(2):153-165.

2. Farabi SMV, Afraei Bandpey MA, Daryanabard Gh, et al. Comprehensive study of the southern of Caspian Sea ecosystem with aim of establishing marine cage fish culture and aquaculture development. Iranian Fisheries Science Research Institute (IFRO). Approved Number: 14-76-12-9256. $2017 ; 140$.

3. Farabi SMV, Nasrolahzadeh Saravi H, Pourang N.et al. Environmental impact assessment of fish culture in floating cage in the south of Caspian Sea (Mazandaran Province). Iranian Fisheries Science Research Institute (IFRO). 2018;150.

4. Buschmann AH, RiquelmeVA, Hernández-González MC. et al. A review of the impacts of salmonid farming on marine coastal ecosystems in the southeast Pacific. ICES J Mar Sci. 2006;63(7):1338-1345.

5. Sara G, Scilipoti D, Mazzola A, et al. Effects of fish farming waste to sedimentary and particulate organic matter in asouthern Mediterranean area (Gulf of Castellammare, Sicily): amultiple stable isotope study $(\delta 13 \mathrm{C}$ and 15 N). Aquaculture. 2004;234(1-2):21-199.

6. Gowen RJ. Managing eutrophication associated with aquaculture development. Journal of Applied Ichthyology .1994;10(4):242-257.
7. Boyd CE, Queiroz JF, Nitrogen, phosphorus loads vary by system. USEPA should consider system variables in setting new effluent rules. Global Aquaculture Advocate. 2001;4(6):84-86.

8. Nash CE, Burbridge PR, Volkman JK. Guidelines for ecological risk assessment of marine fish aquaculture. U.S. Department of Commerce. NOAA Technical Memorandum NMFS-NWFSC-71.

9. Tett P. Fish farm waste in the ecosystem. Aquaculture in the Ecosystem Springer. 1990;3:1-46.

10. Johansson T. Phosphorus emissions from fish farms: Observed and predicted effects. Comprehensive Summaries of Uppsala Dissertations from the Faculty of Science and Technology. Uppsala. ISBN. 2001;91554-5114-4.

11. Hargrave BT. Far-field environmental effects of marine finfish aquaculture. Canadian Technical Report of Fisheries and Aquatic Sciences. 2003; 1:1-49.

12. Norði G, Glud RN, Gaard E, et al. Environmental impacts of coastal fish farming: Carbon and nitrogen budgets for trout farming in Kaldbaksfjørður (Faroe Islands). Marine Ecology Progress .2011;431:223-241.

13. Olsen L, Holmer M, Olsen Y. Perspectives of nutrient emission from fish aquaculture in coastal waters: Literature review with evaluated state of knowledge. Final Report FHF project no. 542014. The Fishery and Aquaculture Industry Research Fund, Oslo, Norway.2008.

14. AOAC International. Official methods of analysis of AOAC International. Gaithersburg, MD, USA, Association of Analytical Communities. 2000. 17 th edition.

15. Tacon AGJ. Standard method for nutritional and feeding of farmed fish and shrimp. Argent librations press. Redmond, Wash, 1: 117.

16. De Silva SS, Anderson TA, Fish nutrition in aquaculture. Springer Science.1995; 1: 320.

17. Ackefors H, Enell M. Discharge of nutrients from Swedish fish farming to adjacent sea areas. Ambio. 1990;19(1):28-35.

18. Enell M. Environmental impact of nutrients from nordic fish farming Water Scienceand Technology. 1995;31(10):61-71.

19. Reftsie S, Baeverfjord G, Seim R.R. et al. Effects of dietary yeast cell wall $\beta$-glucans and MOS on performance, gut health, and salmon lice resistance in Atlantic salmon (Salmo salar) fed sunflower and soybean meal. Aquaculture. 2010;305(1-4):109-116.

20. Pratoomyot J, Bendiksen EA, Bell JG, et al. Effects of increasing replacement of dietary fishmeal with plant protein sources on growth performance, and body lipid composition of Atlantic salmon (Salmo salar L.). Aquaculture. 2011;316:44-52.

21. Burr GS, Wolters WR, Barrows et al. Evaluation of a canola protein concentrate as a replacement for fishmeal and poultry by-product meal in a commercial production diet for Atlantic salmon (Salmo salar). Int. Aquat. Res. 2013;5(5):1-8.

22. Pulatso S. Estimation of the Nitrogen-Phosphorus Load Caused by Rainbow Trout (Oncorhynchus mykiss Walbaum, 1792) Cage-Culture Farms in Kesikköprü Dam Lake: A Comparison of Pelleted and Extruded Feed. Turk. J. Vet. Anim. Sci. 2008;32(6):417-422. 